\title{
Analysis of Safety about the Jet Flow Field of Automatic Weapon
}

\author{
Dong-peng Xian \\ School of Mechanical Engineering, \\ Nanjing University of Science and Technology, \\ Nanjing,210094,China \\ xiandongpeng1@163.com \\ Jia-sheng Li \\ School of Mechanical Engineering, \\ Nanjing University of Science and Technology, \\ Nanjing, 210094,China \\ ljs1986.student@sina.com
}

\author{
Zhen-qiang Liao \\ School of Mechanical Engineering, \\ Nanjing University of Science and Technology, \\ Nanjing,210094,China \\ zqliao1013@mail.njust.edu.cn \\ Jie Song \\ School of Mechanical Engineering, \\ Nanjing University of Science and Technology, \\ Nanjing,210094,China \\ songj86@sohu.com
}

\section{NUMERICAL ANALOGY}

\begin{abstract}
In the structure of reducing the recoil force by jet gas for auto-weapon, the nozzle section is expansion. Within the nozzle, the state of nozzle flow will change, when high temperature and high pressure, high speed gunpowder gas get through the expansion section. The gas is directed to weapons rear through the nozzle, therefore, the objects of handheld or unmanned weapons are impacted by gunpowder particles spraying at a high speed from the nozzle. In order to analyze the safety of the jet flow field of unmanned automatic weapon, establish the axisymmetric two-dimensional model of the outer flow field. Analyze the results of numerical simulating calculation, find out the speed, pressure, temperature and other key parameters distributions of jet flow field and optimize the structure of nozzle and jet. Ensure recoil reduction l efficiency, at the same time ensure the safety.
\end{abstract}

Keywords-nozzle; jet flow field; recoil reduction; safety

\section{INTRODUCTION}

Nozzle is usually used in missiles and aircraft, and control attitude of the rocket through the thrust vector. Now the nozzle is also used in automatic weapons, for example: recoilless guns, $R T$-20 sniper rifle, etc. Within the nozzle, the state of nozzle flow will change, due to the relationships between the airflow velocity, pressure and area, when high temperature and high pressure, high speed propellant gas gets through the expansion section $^{[1,2]}$. To improve the recoil reduction 1 efficiency, we should as far as possible increase the speed of the propellant gas, but it will damage the objects of weapons traumatic by the high flow speed and pressure, and it will ablation the objects by high temperatures. So we should optimize the structure of nozzle, ensure the recoil reduction efficiency, at the same time ensure the safety. In recent years, intelligence weapon system, such as UAV, rapids development and increasingly become an important strength.

\section{A. Control equation}

There is a little of chemical combustion of gunpowder particles and chemical combustion of high temperature gunpowder gas, when the propellant gas flows in the nozzle. Due to guide holes opening late, the gunpowder particles almost complete combustion, after the propellant gas in the chamber has entered into the nozzle. The results of two-dimensional axisymmetric simulation and three-dimensional flow field simulation are near, so we should legitimately simplify the physical model. In comparison to the calculation of finite rate chemical reaction, numerical calculation of two-dimensional axisymmetric inviscid Euler equation is simple, and can achieve the accuracy of system analysis.

Control equation ${ }^{[3]}$ :

$$
\frac{\partial E}{\partial t}+\frac{\partial F}{\partial \xi}+\frac{\partial G}{\partial \eta}=0
$$

Where

$$
\begin{aligned}
& E=\mathrm{J}^{-1}\left(\rho \text { pu } \rho v \quad \rho \mathrm{h}_{0}-\mathrm{p}\right)^{T} \\
& F=\mathrm{J}^{-1}\left(\begin{array}{llll}
\rho U & \rho U u+\xi_{\mathrm{x}} \mathrm{p} & \rho \mathrm{U} v & \rho \mathrm{Uh}_{0}
\end{array}\right)^{T} \\
& G=\mathrm{J}^{-1}\left(\begin{array}{llll}
\rho \mathrm{V} & \rho \mathrm{Vu} & \rho \mathrm{V} v+\eta_{y} \mathrm{p} & \rho \mathrm{Vh}_{0}
\end{array}\right)^{T} \\
& \mathrm{U}=\xi_{\mathrm{x}} \mathrm{u}+\xi_{\mathrm{y}} v ; \mathrm{V}=\eta_{\mathrm{x}} \mathrm{u}+\eta_{\mathrm{y}} v
\end{aligned}
$$

Here: $\rho, p, u, v$ and $h_{0}$ respectively represent density, pressure, rotation adult axial and radial velocity components 
and specific total enthalpy, $\mathrm{h}_{0}=\mathrm{e}+(\mathrm{p} / \mathrm{\rho})+\left(\mathrm{V}^{2} / 2\right)$, e is specific internal energy, the total velocity is $\mathrm{V}^{2}=\mathrm{u}^{2}+\mathrm{v}^{2}$.

$$
\begin{gathered}
e=\frac{\mathrm{p}}{\gamma-1}+\frac{1}{2} \rho\left(\mathrm{u}^{2}+v^{2}\right) \\
\mathrm{p}=\rho \mathrm{RT}
\end{gathered}
$$

$\gamma$ is gas specific heat ratio, and $\mathrm{R}$ is gas constant.

\section{B. Numerical method}

The finite volume method that disperses integral conservation equation is the solving method which makes integral conservation equation to approximate algebraic equation. Above all, the formula (1) is rewritten to integral conservation equation.

Formula (1) can be written as:

$$
\frac{\partial U}{\partial \mathrm{t}}+\nabla \cdot(F \mathrm{i}+G \mathrm{j})=0
$$

Formula (4) is integrated in the control volume $\Omega_{\mathrm{ij}}$.

$$
\frac{\partial \bar{U}_{\mathrm{i}, \mathrm{j}}}{\partial \mathrm{t}} \Omega_{\mathrm{ij}}+\oint_{\partial \Omega_{\mathrm{ij}}}(F \mathrm{i}+G \mathrm{j}) \cdot \mathrm{n} d \mathrm{l}=0
$$

where

$$
\begin{gathered}
\bar{U}_{\mathrm{i}, \mathrm{j}}=\frac{\int_{\Omega \mathrm{ij}} U d \mathrm{x} d \mathrm{y}}{\Omega_{\mathrm{ij}}} \\
\oint_{\partial \Omega_{\mathrm{ij}}}(F \mathrm{i}+G \mathrm{j}) \cdot \mathrm{n} d \mathrm{l}=\sum_{\mathrm{s}=1}^{4} \int_{\mathrm{A}_{\mathrm{s}-1}}^{\mathrm{A}_{\mathrm{s}}}\left[\mathrm{n}_{\mathrm{x}} F(U)+\mathrm{n}_{\mathrm{y}} G(U)\right] d \mathrm{l}
\end{gathered}
$$

Here, $\mathrm{n}$ is the normal unit vector; $\mathrm{s}$ represents the four edges of control body, $\mathrm{A}_{\mathrm{s}}$ represents the angular point of control body.

Formula (5) can be written as:

$$
\frac{\partial \bar{U}_{\mathrm{i}, \mathrm{j}}}{\partial \mathrm{t}} \Omega_{\mathrm{ij}}+\sum_{\mathrm{s}=1}^{4} \int_{\mathrm{A}_{\mathrm{s}-1}}^{\mathrm{A}_{\mathrm{s}}}\left[\mathrm{n}_{\mathrm{x}} F(U)+\mathrm{n}_{\mathrm{y}} G(U)\right] d \mathrm{l}=0
$$

\section{Computational domain and meshing}

Due to the propellant gas spray at a supersonic speed from the jet, a large compression wave forms out of the nozzle, and keeps spreading. In order to obtain the variation about pressure of jet flow field, we should appropriately increase the area of the nozzle, lest calculation model is the influenced by boundary. The width of computational domain is eight times as big as the diameter of nozzle section and the length of computational domain is ten times as big as the diameter of nozzle section. The grid of nozzle is divided into airway area, nozzle area and jet area in the calculation area, because the fluidic movement is different. Due to the propellant gas rapidly accumulating, the pressure rapidly increasing at the entrance of nozzle and the parameters changing greatly in the nozzle, the grid of airway area and nozzle area is divided thick. But the grid of jet area is divided thin, due to the pressure reducing rapidly. The mesh is shown in Fig. 1:

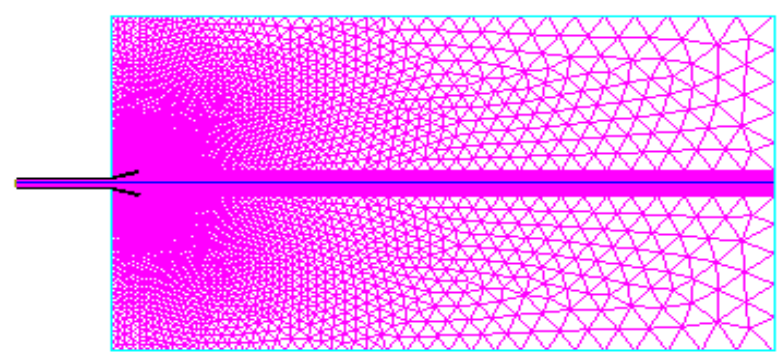

Fig. 1 The element computation model

\section{Initial condition}

In the calculation of jet flow field, air state variable of normal temperature and ordinary pressure is the Initial condition, expressions are as formula (9):

$$
\left.\begin{array}{r}
\mathrm{u}_{\mathrm{g}}(\mathrm{x}, 0)=0 \\
\mathrm{u}_{\mathrm{p}}(\mathrm{x}, 0)=0 \\
\mathrm{p}(\mathrm{x}, 0)=\mathrm{p}_{0} \\
\mathrm{~T}_{\mathrm{g}}(\mathrm{x}, 0)=\mathrm{T}_{0} \\
\mathrm{~T}_{\mathrm{p}}(\mathrm{x}, 0)=\mathrm{T}_{0} \\
\hat{\rho}_{\mathrm{g}}=\frac{\mathrm{p}_{0}}{\alpha \mathrm{p}_{0}+\mathrm{RT}_{0}} \\
\varphi(\mathrm{x}, 0)=\mathrm{f}(\mathrm{x})
\end{array}\right\}
$$

\section{E. Boundary condition}

In the calculation of jet flow field, boundary conditions include inlet boundary, outlet boundary and wall boundary, as formula (10):

$$
\mathrm{p}_{0}=\mathrm{p}_{\mathrm{s}}\left(1+\frac{\gamma-1}{2} \mathrm{M}^{2}\right)^{\frac{\gamma}{\gamma-1}}
$$

Here, $\mathrm{p}_{0}$ is actual total pressure, Inlet boundary: pressure at the entrance of guide holes is calculated by Matlab. Input the static pressure, total temperature, flow direction and other conditions. The total pressure is calculated by the static pressure for the supersonic flow. $\mathrm{p}_{\mathrm{s}}$ is actual static pressure, $\mathrm{M}$ is Mach number, $\gamma$ is specific heat ratio.

Outlet boundary: Propellant gas accelerated in the nozzle will spray from jet at a supersonic speed, so the pressure at outlet boundary will be calculated by the interior of flow field.

Wall boundary: The pressure use the equation as $\partial \mathrm{p} / \partial \mathrm{n}=0$, and the condition of temperature use the equation as $\partial \mathrm{T} / \partial \mathrm{n}=0$.

\section{F. Simulation result}

1) Temperature-plotting of jet flow field: The figures batch showing, the temperature of jet flow field first increases 
and then decreases along the axis of nozzle, and weakened gradually, and maximize at $0.32 \mathrm{~ms}$.
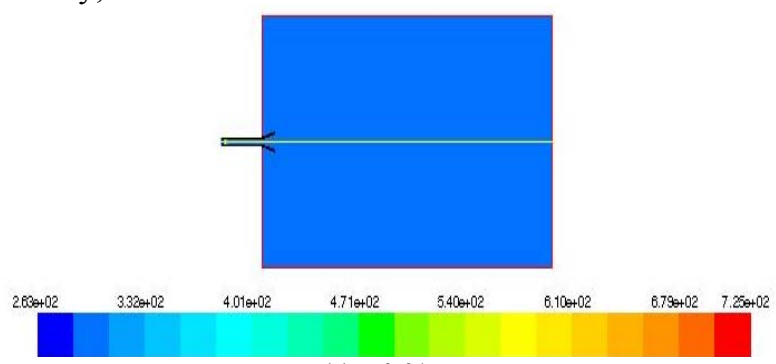

(a) $\mathrm{t}=0.01 \mathrm{~ms}$
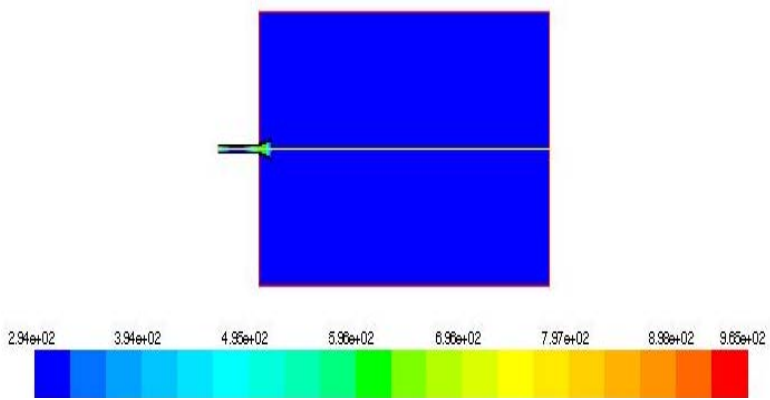

(b) $\mathrm{t}=0.06 \mathrm{~ms}$
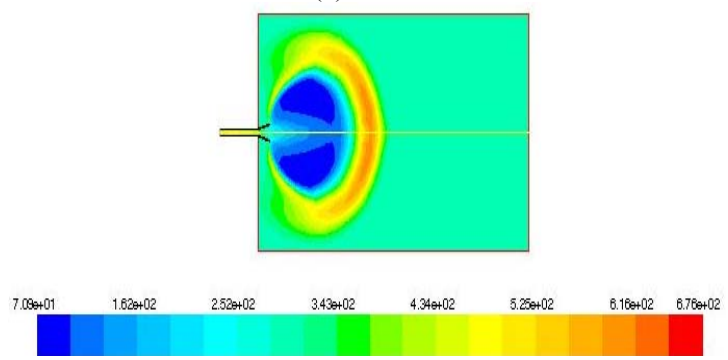

(c) $\mathrm{t}=0.32 \mathrm{~ms}$
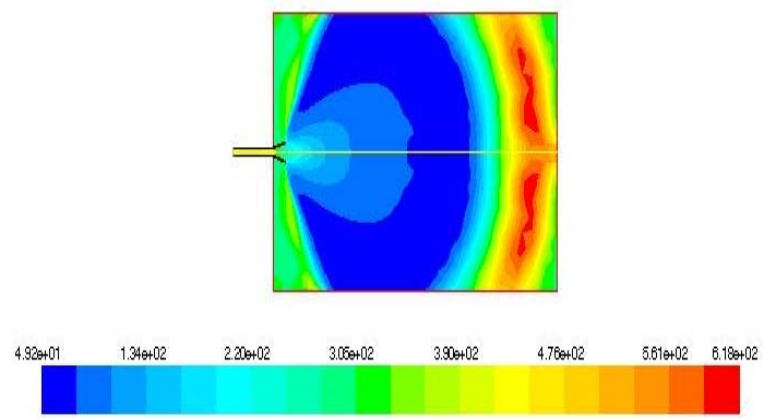

(d) $\mathrm{t}=0.70 \mathrm{~ms}$

Fig. 2 Temperature-plotting of jet flow field
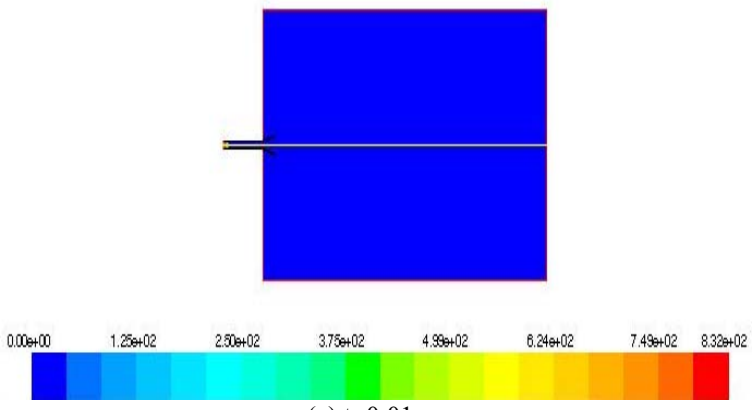

(a) $\mathrm{t}=0.01 \mathrm{~ms}$
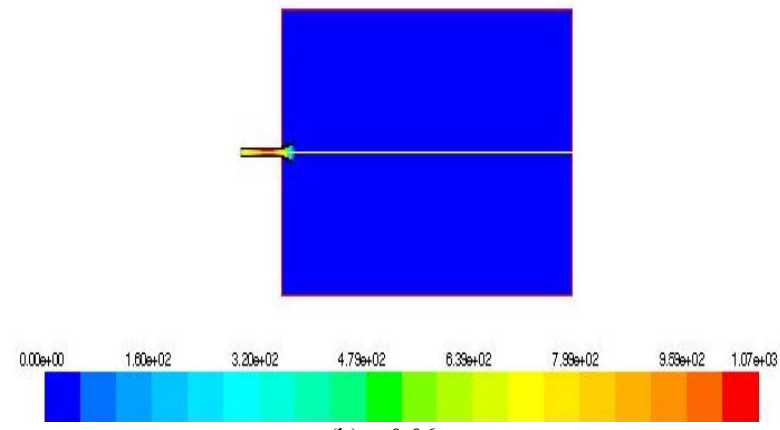

(b) $\mathrm{t}=0.06 \mathrm{~ms}$
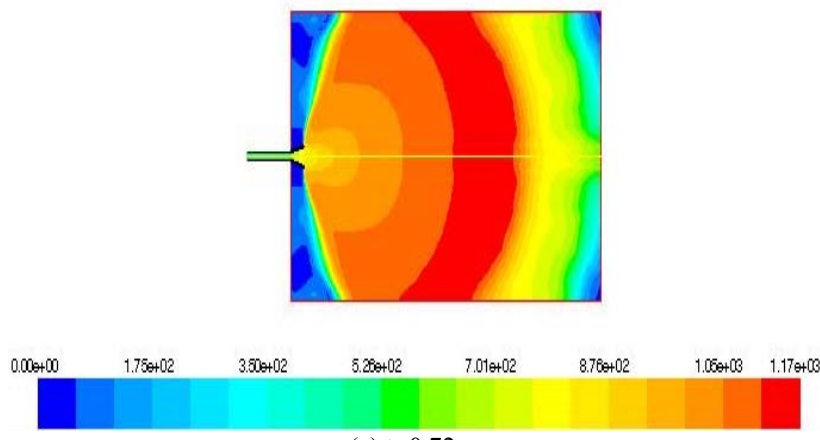

(c) $\mathrm{t}=0.72 \mathrm{~ms}$

Fig. 3 Velocity-plotting of jet flow field

2) Velocity-plotting of jet flow field: The figures batch showing, the speed of the gunpowder gas is high velocity in the axis of nozzle, but it is very low in the radial direction, after spraying from nozzle.

\section{CONCLUSIONS}

(1) The flames is engendered and erosions the objects around the jet when high temperature and high pressure gas is spouting from the jet. The figures show that the maximum temperature of jet flow field is $676 \mathrm{~K}$. The max hot spot far below the hot spot which the body can tolerate, because the action time about the propellant gas of jet flow field is very short. So, the flame could not damage the body.

(2) The propellant gas forms a compression wave when the gunpowder blasts in the air and water, and it leads to the density, pressure and temperature increasing rapidly and spreading rapidly. So the shock wave is formed and could damage the project.

We can see that, Because the duration of shock wave is limited and the Critical overpressure of jet flow field can not superimpose, so the safe distance could not increase. 
TABLE 1 RESULT OF JET FLOW FIELD ${ }^{[4]}$

\begin{tabular}{c|c|c|c|c}
\hline & $\begin{array}{c}\text { Critical overpressure } \\
(\mathrm{MPa})\end{array}$ & $\begin{array}{c}\text { Critical distance } \\
(\mathrm{mm})\end{array}$ & $\begin{array}{c}\text { time of shock waves } \\
\text { reaching critical distance } \\
(\mathrm{ms})\end{array}$ & $\begin{array}{c}\text { Shock wave positive pressure } \\
\text { duration }(\mathrm{ms})\end{array}$ \\
\hline $\begin{array}{c}\text { human body without } \\
\text { injury }\end{array}$ & 0.005 & 932 & 1.94 & 0.97 \\
\hline glass broken & 0.007 & 886 & 1.85 & 0.82 \\
\hline $\begin{array}{c}\text { human body minor } \\
\text { injuries }\end{array}$ & 0.010 & 804 & 1.76 & 0.77 \\
\hline
\end{tabular}

\section{REFERENCES}

[1] Cengqing Zhao, Yi Jiang. Gas Jet Dynamics[M]. Beijing: Press of Beijing Institute of Technology (1998).

[2] Yuxin Ren, Haixi Chen. Computational Fluid Dynamics Basis[M]. Beijing: Press of Tsinghua University (2006).
[3] Xudong Gao. Numerical Simulation of Complicated Spinning-Lateral jet Flow Field[D]. Nanjing: Ph. D. Dissertation of Nanjing University of Science and Technology (2002).

[4] Yang Chen. Technology of Reducing the Recoil Force by Jet Gas for Weapon System[D]. Nanjing: Ph. D. Dissertation of Nanjing University of Science and Technology (2009)

[5] John D. Anderson. Computational Fluid Dynamics[M]. Beijing: China Machine Press (2007). 